\title{
Evaluation of fine needle aspiration cytology of lymph nodes in Kathmandu Medical College, Teaching hospital
}

\author{
Hirachand $\mathbf{S}^{1}$, Lakhey $\mathbf{M}^{2}$, Akhter $\mathbf{J}^{3}$, Thapa $\mathbf{B}^{4}$ \\ 1,3,4 Lecturer, ${ }^{2}$ Associate Professor, Department of Pathology, Kathmandu Medical College, Sinamangal, Nepal.
}

\begin{abstract}
Background: Fine Needle Aspiration Cytology (FNAC) is a simple and rapid diagnostic technique. Because of early availability of results, simplicity, minimal trauma and complications, the aspiration cytology is now considered a valuable diagnostic aid and is part and parcel of a pathologist's repertoire.

Objectives: The aim of the study was to evaluate the results of fine needle aspiration cytology (FNAC) of lymph nodes in our institution in comparison to result of histopathology.

Materials and methods: The present study on 130 patients of lymphadenopathy was conducted in the Department of Pathology Kathmandu Medical College Teaching hospital, Kathmandu from June 2006 to May 2008 (2 years).

Results: In this series of FNAC cervical lymph nodes were 66 (50.76\%), and axillary lymph nodes were 20 (15.38\%). Male to female ratio of the patients was 1: 0.9. Th age of patients ranged from 3 to 85 years. FNAC diagnosis was found to be as follows : reactive hyperplasia 54( 41.55\%), tubercular lymphadenitis 36 (28\%), metastatic carcinoma 16 (12.3\%), granulomatous lymphadenitis 12 ( $9.2 \%)$, lymphoma $8(6 \%)$ and suppurative lymphadenitis $4(3 \%)$. Out of 28 cases of FNAC 26 (92.85\%) were consistent with histopathological diagnosis of tubercular lymphadenitis. In metastatic carcinoma to lymph nodes sensitivity and specificity of FNAC were $100 \%$ each.

Conclusion: FNAC is useful and reliable in diagnosing neoplastic and non- neoplastic lesions of lymph nodes. It helps in planning surgery for malignant cases, where definitive operative intervention can be performed in one session.
\end{abstract}

Key words: FNAC, lymphadenopathy.

$\mathrm{L}$ ymphadenopathy is one of the commonest clinical presentations of patients, attending the outdoor department. The aetiology varies from an inflammatory process to a malignant condition ${ }^{1}$.

Fine needle aspiration cytology (FNAC) is a simple and rapid diagnostic technique. Because of early availability of results, simplicity, minimal trauma and absence of complications, the aspiration cytology is now considered a valuable diagnostic aid. The cytomorphological features collaborates with histopathology and has qualities of a micro-biopsy ${ }^{2,3}$.

The present study is undertaken to evaluate the usefulness of FNAC as a diagnostic tool in cases of lymphadenopathy and study the different cytomorphological patterns associated with various lymphadenopathies ${ }^{4}$.

\section{Material and methods}

The present study on 130 patients of lymphadenopathy was conducted in the Department of Pathology, Kathmandu Medical college, Teaching hospital, Kathmandu from June 2006 to May 2008 ( 2 years ).
FNAC was performed using a 23-gauge needle. An average 2 passes was performed and minimum 5 slides were prepared. Two slides were air dried and stained by Giemsa stain, and 2 slides were fixed in alcohol and then stained with PAP stain. One slide was kept unstained in each case and Ziehl-Neelsen staining was performed where a cytologic diagnosis of granulomatous disease was made. The aspiration smears from the enlarged lymph nodes were studied to arrive at a probable diagnosis. The cytological results were compared with histological findings, whenever possible.

\section{Results}

During this period, a total 130 FNAC's from lymph nodes were performed. Only 5 cases were in the paediatric age group. Seventeen patients were in range of 13 to 20 years. Sixty cases belonged to age group

\footnotetext{
Correspondence

Dr. Suspana Hirachand

Lecturer, Department of Pathology,

Kathmandu Medical College Teaching Hospital

Kathmandu, Nepal

E-mail: suspi1974@hotmail.com
} 
between 21 to 40 years. Thirty Six patients were in the group 41 to 60 years. Eight were in the group between 61 to 80 years and only 4 patients were above the age of 81 years. Sixty eight patients were males and 62 , females.

The commonest site of lymphadenopathy was in neck constituting 66 cases. Among the remaining cases, 20 were axillary, 18 submandibular, 14 supraclavicular and 12 inguinal lymph nodes.

FNAC diagnosis was found to be as follows : reactive hyperplasia $54(41.5 \%)$, tubercular lymphadenitis 36 $(28 \%)$, metastatic carcinoma $16(12.3 \%)$, granulomatous inflammation $12(9.2 \%)$, lymphoma $8(6 \%)$ and Suppurative lymphadenitis 4 (3\%).

The criteria by which a diagnosis of reactive hyperplasia was established included high cell density, polymorphic patterns of cells and considerable number of tingible bodies macrophages.

The aspirates from lymphnodes were diagnosed as tubercular lymphadenitis based on the presence of epithelioid cell granuloma and caseous necrosis with or without langhan's giant cells in a milieu of parent lymphoid cells. Among these, 18 cases were ZiehlNeelsen staining positive.

Granulomatous lymphadinitis was diagnosed on the presence of epithelioid cell granuloma with or without giant cells and with absence of necrosis.

Suppurative lymphadenitis cases showed predominantly polymorphonuclear leukocytes, necrotic debris and other lymphoid cells.

Out of total 16 cases of metastasis to lymph node, 12 $(75 \%)$ were of metastatic squamous cell carcinoma with

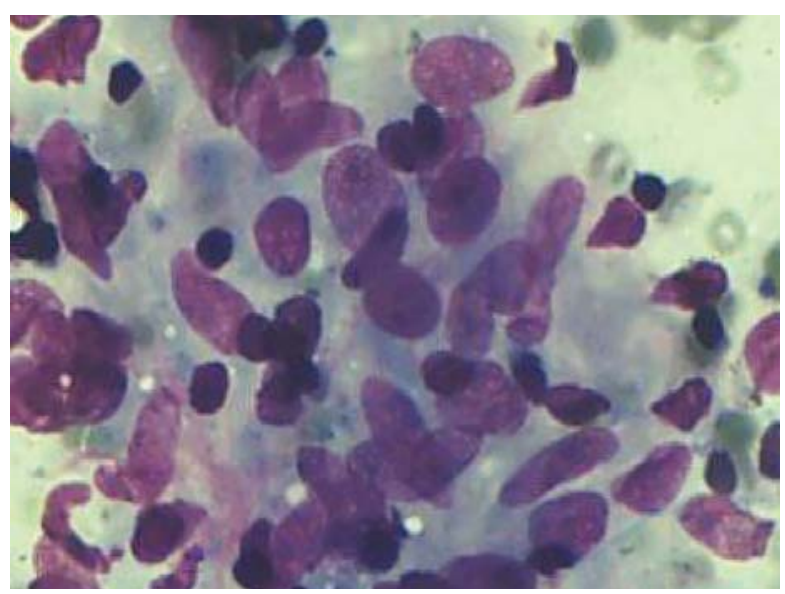

Fig 1: Cytology smear : epithelioid cell granuloma (MGG x 400) oral cavity being the commonest site (8) followed by lung (4). Four (25\%) were of metastatic adenocarcinoma from stomach.

Lymphoma cases were total $8(6 \%)$ of which 6 were Non-Hodgkin's lymphoma and 2 were Hodgkin's Disease.

Non-Hodgkin's lymphoma smears showed a monocellular pattern, consisting of lymphoblasts or lymphocytes. Hodgkin's lymphoma showed a mixed cell population with characteristic Reed-sternberg giant cell.

A correlation was done in 72 cases which were diagnosed both by FNAC and histopathology. Out of 72 cases, 28 were of reactive hyperplasia, 26 of which were true positive and 2 were false positive which turned out to be a lymphoma on histological examination. The result show $100 \%$ sensitivity, where as specificity was found to be $95.65 \%$.

In 36 cases of tubercular lymphadenitis, histological corroboration was seen in 20 cases. One case which was diagnosed as tuberculous on FNAC was found to be lymphoma on histopathological examination. Sensitivity and specificity was found to be $100 \%$ each.

Out of the 24 malignant lesions in which cytohistological correlation was done, 8 were of lymphomas and 16 of metastatic carcinoma. Out of 8 cases of lymphoma, 2 were diagnosed as reactive hyperplasia on histopathology. Sensitivity and specificity of FNAC in cases of lymphoma was $80 \%$ and $100 \%$ respectively.

In cases of metastatic carcinoma to lymph nodes, all 16 cases showed exact corroboration with histopathology. Thus sensitivity and specificity was $100 \%$ each.

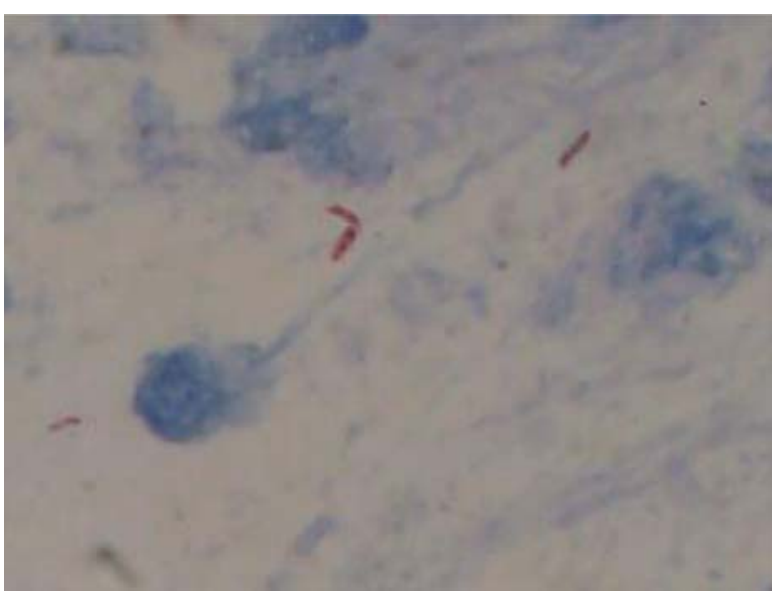

Fig 2: Acid fast bacilli (ZN stain x 1000) 


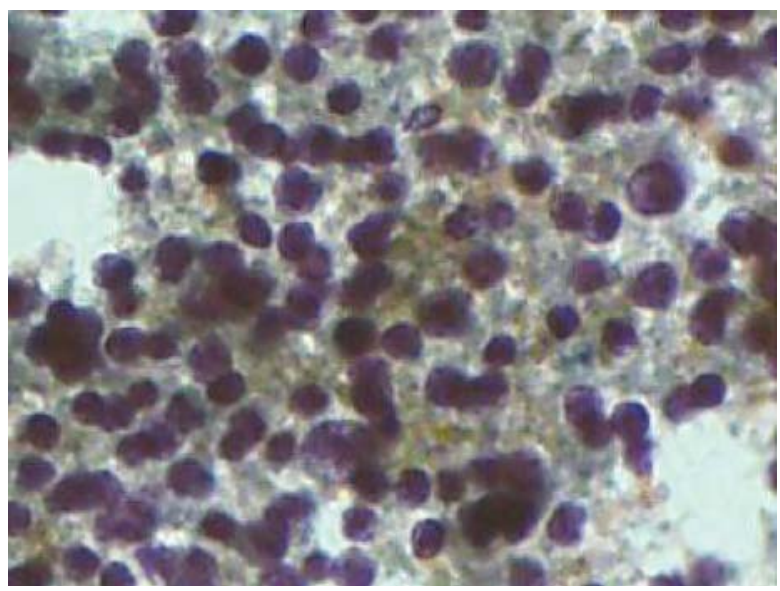

Fig 3: Cytology smear : NHL (Pap x 400)

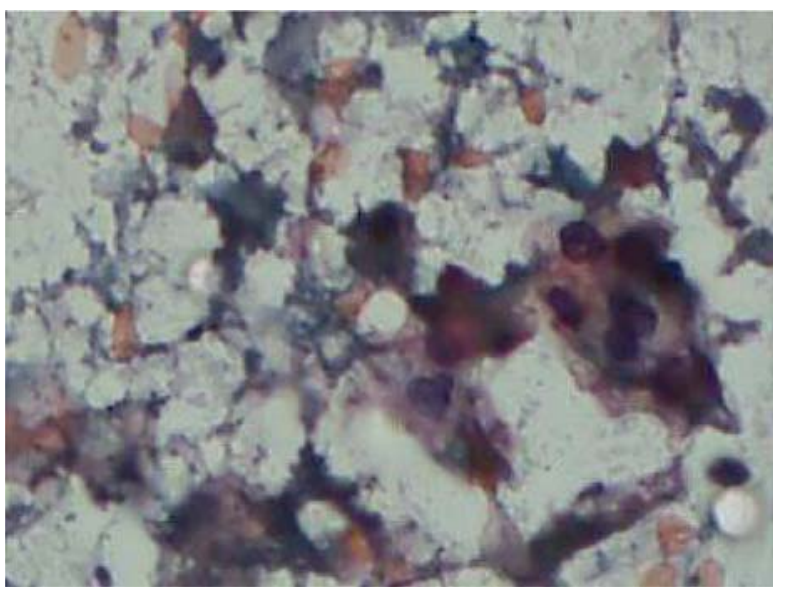

Fig 4: Cytology smear : Squamous cell carcinoma. (Pap x 400)

Table1: Cytologic results of 130 cases

\begin{tabular}{|l|c|c|}
\hline Cytological Results & No.of Cases & Percentage \% \\
\hline Reactive hyperplasia & 54 & 41.5 \\
\hline Tubercular lymphadenitis & 36 & 28.0 \\
\hline Granulomatous lymphadenitis & 12 & 9.2 \\
\hline Metastatic carcinoma & 16 & 12.3 \\
\hline Lymphoma & 08 & 6.0 \\
\hline Suppurative Lymphadenitis & 04 & 3.0 \\
\hline Total & $\mathbf{1 3 0}$ & $\mathbf{1 0 0}$ \\
\hline
\end{tabular}

Table 2: Cyto-histo corroboration in 72 cases

\begin{tabular}{|l|c|c|c|c|c|}
\hline \multirow{2}{*}{ Cytological Diagnosis } & \multirow{2}{*}{ No. of Cases } & \multicolumn{4}{|c|}{ Histological Diagnosis } \\
\cline { 3 - 6 } & & $\begin{array}{c}\text { Reactive } \\
\text { hyperplasia }\end{array}$ & $\begin{array}{c}\text { Tubercular } \\
\text { lymphadenitis }\end{array}$ & Lymphoma & $\begin{array}{c}\text { Metastatic } \\
\text { carcinoma }\end{array}$ \\
\hline Reactive hyperplasia & 28 & 26 & & 02 & \\
\hline Tubercular Lymphadenitis & 20 & & 19 & 01 & \\
\hline Lymphoma & 08 & 02 & & 06 & 16 \\
\hline Metastatic Carcinoma & 16 & & & & $\mathbf{0 9}$ \\
\hline Total & $\mathbf{7 2}$ & $\mathbf{2 8}$ & $\mathbf{1 9}$ & $\mathbf{1 6}$ \\
\hline
\end{tabular}

\section{Discussion}

Fine needle aspiration cytology is a simpler, safe, cost effective, time saving and at same time it suggests positive finding 5 . The patient is free from the scar of operation.

In our study, male to female ratio was 1:0.9, with male preponderance, which was also seen in other studies ${ }^{6,7}$.

The lesions arising in the lymph node can be found in patients ranging from early to advanced age. In our study the youngest patient was 3 years old and oldest was 85 years of age. These figures come in close comparison to other workers ${ }^{2}$.

As regards the site of FNAC, cervical lymph node was the commonest site of involvement, as observed by other workers ${ }^{1,3,6}$.

Out of total 130 cases, $106(81.5 \%)$ cases were benign and $24(18.5 \%)$ cases were malignant lesions. These findings correlate well with the results reported by Sarda et al and Pamra SR et $\mathrm{a}^{8,9}$. However Steel et 
$\mathrm{al}^{2}$ reported $59 \%$ cases of malignant lesions and 34\% cases of benign lesions. This may be attributed to the fact that western countries, where these studies were carried out show predominance of malignant conditions over benign conditions. In our study bulk of diseases are of reactive nature due to infections and of tubercular lesions, which are uncommon in western countries.

Majority of cases were reactive in nature, 54(41.5\%) cases which correlated well with findings of other workers $^{10}$.

Our findings constituted 36 (28\%) cases of tubercular lymphadenopathy, which was also observed by Tilak et $\mathrm{al}^{11}$.

We report $8(6.1 \%)$ cases of lymphoma which correlated with findings of Tilak et $\mathrm{al}^{11}$, who reported an incidence of $5.6 \%$, where as Egea et al ${ }^{10}$, have reported $9.5 \%$ cases of lymphoma in their studies.

Maximum number of correct diagnosis was obtained in metastatic nodes. There was not a single case overdiagnosed or underdiagnosed in this group (sensitivity adn specificity of $100 \%$ each).

In our study, the majority of the metastatic nodes sampled were squamous cell carcinoma. Hajdu et $\mathrm{al}^{12,}$ in their study also noted that the common type of metastatic carcinoma to lymph node was squamous cell carcinoma, followed by adenocarcinoma. Similar findings were reported by Engzell et al ${ }^{8,13}$.

\section{Conclusion}

FNAC of lymph nodes proved to be useful tool in diagnosing both neoplastic and non-neoplastic lesions. It helps in planning surgery for malignant cases, where definitive operative intervention can be performed in one session.

\section{References}

1. Pandit AA, Candes FP, Khubchandani SR. Fine needle cytology of lymphnodes. J. Postgrad. Med. 1987; 33: 134-6.

2. Steel BL, Schwartz MR, Ibrahim R. Fine needle aspiration biopsy in diagnosis of lymphadenopathy in 1,103 patients. Acta Cytologica. 1995; 39: 76-81.
3. Ahmad SS, Akhtar S, Akhtar K, Naseem S, Mansoor T. Study of fine needle aspiration cytology in lymphadenopathy with special reference to Acid-fast staining in cases of tuberculosis. JK Science. 2005; 7: 1-4.

4. Metre MS, Jayaram G. Acid fast bacilli in aspiration smears from tuberculous lymphnodes. Acta Cytologica. 1987; 39: 76-81.

5. Saluja JG, Ajinyka MS. Comparative study of fine needle aspiration cytology, histopathology and bacteriology of enlarged lymphnode. Bombay hospital journal. 2000; 42( 2): 1-7.

6. Patra AK, Nanda BK, Mahapatra BK, Panda AK. Diagnosis of lymphadenopathy by fine needle aspiration cytology. Ind. J. Pathol. and Microbiol. 1983; 26: 273-8.

7. Ansari SM, Zeenal AP, Tyagi SP. Tuberculous lymphadenopathy. Indian Paediatr. 1981; 18: 293-6.

8. Sarda AK, Bal S, Singh MK, Kapur MM. Fine needle aspiration cytology as a preliminary diagnostic procedure for asymptomatic cervical lymphadenopathy. JAPI. 1990; 38(3):203-5.

9. Pamra SR, Baily GVS, Gupta SP et al. Cervical lymphadenopathies. Ind. J.Tub. 1987: 96-100.

10. Egea AS, Gonzalez MAM et al. Usefulness of Light microscopy in lymphnode fine needle aspiration biopsy. Acta Cytologica. 2002; 46: 368-9.

11. Tilak V, Dhadel AV, Jain R. Fine needle aspiration cytology of head and neck masses. Ind. J. Pathol. and Microbiol. 2002;45(1):2350 .

12. Hajdu SI, Melamed MR. The diagnostic value of aspiration smears. Am.J clin. Path. 1973; 59: 350-4.

13. Engzell V, Jakobsson PA, SigurdsonA, Zajidek. Aspiration biopsy of metastatic carcinoma in lymphnode of the neck. Acta Otolaryngol. 1971;72: 138-47. 